\title{
Analysis of Critical Delay Factors in Construction Projects with a Focus on Qatar
}

\author{
Aldana Abdulla Alsulaiti ${ }^{1, ~ *, ~ L a o u c i n e ~ K e r b a c h e ~}{ }^{2}$ \\ ${ }^{1}$ Department of Infrastructure and Civil Projects, Qatar Petroleum, Doha, Qatar \\ ${ }^{2}$ Division of Engineering and Decision Sciences, College of Science and Engineering, Hamad Bin Khalifa University and HEC Paris, Doha, \\ Qatar
}

Email address:

d.al-sulaiti@hotmail.com (A. A. Alsulaiti), lakerbache@hbku.edu.qa (L. Kerbache)

*Corresponding author

\section{To cite this article:}

Aldana Abdulla Alsulaiti, Laoucine Kerbache. Analysis of Critical Delay Factors in Construction Projects with a Focus on Qatar. International Journal of Business and Economics Research. Vol. 9, No. 3, 2020, pp. 130-139. doi: 10.11648/j.ijber.20200903.16

Received: April 10, 2020; Accepted: May 3, 2020; Published: May 14, 2020

\begin{abstract}
The growth of the construction industry, a major driving force for the Qatar National Vision (QNV) 2030, is assessed in terms of its ability to maintain timely delivery, premium quality, and rigorous cost control. The purpose of this study was to assess the critical delay factors in Qatari building construction projects according to complexity level and determine methods to mitigate them. This study focused on three building categories, four- and five-star hotels, core and shell office/commercial buildings, and worship buildings, constituting four complexity levels. The objectives were to determine the relationship between the delay factors and project characteristics to mitigate the associated risks. A critical motivation for the study was the assumption that some projects in Qatar exhibit very high costs per square meter owing to variations in their execution phases. The methodology comprised case studies and interviews with project experts and was articulated around the development of a complexity categorization framework to achieve the study objectives. The findings indicated that projects with similar complexity levels and characteristics have common factors affecting their time performance. The impacts of certain factors such as changes in scope were found to be significant for any building category at either a high or low complexity level, while delay was shown to be smaller for lower complexity projects. The results support the assumption that the very high costs per square meter of some projects in Qatar arise from variations. This paper demonstrates how a carefully designed research methodology using an appropriate framework can enable identification of the most critical delay factors in construction projects according to building category and complexity level. The focus on Qatar enabled the formulation of a series of recommendations for construction industry decision-makers and operators as well as a policy proposals to government entities and major stakeholders to streamline the construction process and mitigate critical delays. The findings of this study provide insights into project time performance in terms of the selected project categories with various complexity levels.
\end{abstract}

Keywords: Construction Delays, Causes of Delays, Project Management, Complexity Level, Qatar

\section{Introduction}

As the global construction industry grows, delays and cost overruns have become some of the most common problems facing construction projects. Because the construction industry is a medium for achieving national visions and goals, project delays are a significant concern and can lead to adverse consequences in terms of hindering economic development, inducing cost overruns via significant capital outlay, litigation, and abandoned projects, and leaving a bad impression on foreign investors based on poor management and weak organizational practices.

Owing to the complex nature and associated risks of construction projects, effective project management plays a pivotal role in the successful completion of such projects. Although projects have been implemented since the first human communities, project management was not distinguished as a profession until the mid-20th century. Rapid advancements in modern technology have made 
project management a critical factor in all projects regardless of scale or complexity.

Project delay, or completion beyond the planned deadline, arises from different factors such as project nature, size, and various dimensions of complexity, including technological advancement. It is therefore crucial to identify primary delay factors to properly manage construction projects and ensure timely performance. As construction projects vary in terms of complexity and nature, the ability to measure these factors at an early stage can deepen the understanding of associated risks and corresponding complexity characteristics. With this deeper understanding, project managers can take the actions necessary to successfully deliver future projects.

Although the impact of construction project complexity on delay has not been widely studied, there is an implicit assumption that delay factors in complex projects differ from those in more straightforward projects, and that the former are more subject to delay than the latter. This, assumption however, needs to be explicitly validated. Furthermore, most studies have linked delay factors to project type but not to underlying project characteristics, which can provide a broader understanding of the issue.

This study investigated common delay factors and their impacts on specific building project categories with the goal of linking delay to various project characteristics and establishing a broader conclusion that can be applied to projects in general. Specifically, this study focused on project complexity level to gain an understanding of underlying project characteristics. The geographic focus of this study was Qatar, which is home to one of the fastest-growing construction markets worldwide. As Qatar prepares to host the FIFA World Cup in 2022 and strives to fulfill the objectives of the Qatar National Vision (QNV) 2030, investments of over USD 220 billion are being made at a rate of nearly USD 500 million per week to develop infrastructure including mega projects such as the Doha Metro, stadiums, and new roads, and bridges, along with key projects such as hotels and leisure and recreational destinations. The rapidly expanding construction sector and the diversity of projects needed to meet the obligations created by the government's economic reform initiatives as well as the QNV and FIFA 2022 World Cup commitments provides an opportunity to investigate the relationship between delay factors in building construction projects and project complexity levels. A critical motivation for this study was the assumption that some projects in Qatar exhibit very high costs per square meter as a result of the complexity of carrying out the execution phase, an assumption that was confirmed by the results of this study and confirmed to be linked to critical delay factors.

\section{Literature Review}

\subsection{Complexity in Construction Projects}

Complexity is difficult to define because it has several connotations. According to Richardson, Lissack, and Cilliers, a system comprising many entities and requiring a high level of interaction among those entities can be classified as a complex system [1].

Wood and Gidado [2] used insight's from Merry's [3] overview to note that complex behaviors that cannot be predicted from knowledge of the individual parts of a system can emerge from several basic rules. One method for discovering such rules is to study how system elements interact with each another and how the system adapts and changes over time. Because construction is a highly risky, dynamic, and challenging industry [4], understanding and analyzing project complexity is critical to ensure effective management [5].

According to Baccarini [5], project complexity can be defined as "consisting of many varied interrelated parts and can be operationalized in terms of differentiation and interdependency." This is applicable to any dimension of the project management process, including organization, environment, technology, information, systems, and decisionmaking. Accordingly, it is crucial to clearly identify the type of complexity of a project.

Complexity has various dimensions in construction projects. Buys explained that complexity can be defined in terms of project size [6], as large projects have more extended execution periods and can experience greater cost and time overruns. Lengthy negotiations to manage inflation, fluctuations in exchange rates, and the costs of the materials affecting the initial project budget can lead to overruns. Similarly, highly complex projects contain complex aggregations of plans, schedules, and estimates. As a result, any omission of critical aspects will increase the risk of modification/change and cause delays. Project complexity can also be classified in terms of the diversity of stakeholders. Different stakeholders will have different interests, leading to long communication channels, inherently slow feedback, disputes, and conflicts. Adequate time and resources must therefore be allotted to successfully integrate these interests.

Based on interviews with several industry experts Gidado [7] proposed that, a complex project can be defined as one that requires the merging of several systems. This can lead to confined sites that are difficult to access and difficulty in clarifying approaches to achieve a desired goal; overcoming these issues requires a significant amount of control, coordination, detailed execution, and appraisal throughout the project management process. Gidado further illustrated that project complexity can be seen from managerial, technological, and operational perspectives [7].

Defining complexity in the project management process is crucial because it determines the selection of project inputs, provides criteria for selecting the right project organizational form, identifies hindrances to meeting project goals, provides a criterion for choosing the correct procurement arrangement, and helps to control, coordinate, and plan project requirements [5].

\subsection{Developed Complexity Categorization Framework}

As complexity is a broad and potentially highly subjective 
term, the types of complexity considered in this study were identified using a framework developed to categorize projects based on a set of complexity characteristics. The selection of characteristics was guided by a literature review and interviews with different field experts, including executives and lead project managers, who had extensive experience with various types of projects. The goal was to use their experience to define complexity while remaining cognizant that the meaning of complexity is not limited to a set of typical characteristics and can vary depending on the unique dimensions and environment of a project.

Three building categories constituting a total of four complexity levels were defined based on the identified complexity characteristics. These categories are:

1. Category 1: Four- and five-star hotels,

2. Category 2: (Groups $A \& B$ ). Core and shell office or commercial buildings including two complexity levels,

3. Category 3: Buildings used for worship.

The factors defining this complexity categorization framework are listed in Table 1.

Table 1. Complexity categorization framework.

\begin{tabular}{|c|c|c|c|c|}
\hline \multirow{2}{*}{ Complexity characteristics } & \multirow{2}{*}{$\begin{array}{l}\text { Category } 1 \text { Four- } \\
\text { to five-star hotel } \\
\text { buildings }\end{array}$} & \multicolumn{2}{|c|}{ Category 2 Commercial/office buildings } & \multirow{2}{*}{$\begin{array}{l}\text { Category } 3 \\
\text { Worship } \\
\text { buildings }\end{array}$} \\
\hline & & Group A & Group B & \\
\hline Project size & $\boldsymbol{Q}^{\mathrm{a}}$ & $0^{\mathrm{a}}$ & & \\
\hline Project cost & $\bullet^{b}$ & $a^{b}$ & & \\
\hline Complex combinations of design, schedule, and estimations & $\boldsymbol{Q}^{\mathrm{c}}$ & $0^{c}$ & & \\
\hline Stakeholders' diversity & $\boldsymbol{Q}^{\mathrm{d}}$ & & & \\
\hline Complex systems interactivity & $\bullet^{\mathrm{e}}$ & & & \\
\hline Project customization & $\bullet^{\mathrm{f}}$ & $e^{\mathrm{f}}$ & $\bullet^{\mathrm{f}}$ & \\
\hline Efficient coordination, control, and monitoring from start to finish & $\boldsymbol{\bullet}^{\mathrm{g}}$ & $0^{\mathrm{g}}$ & $\boldsymbol{0}^{\mathrm{g}}$ & $\boldsymbol{0}^{\mathrm{g}}$ \\
\hline Total \# of complexity points & seven & five & two & one \\
\hline
\end{tabular}

Note: The complexity categorization is based on a set of identified characteristics.

a Project size above 28,000 square meters (built-up area).

b Project cost above 90 million Qatari Riyal.

c Project contains complex combinations of design, schedule, and estimation.

d Project involves diverse stakeholders with high levels of power and interest.

e Project contains a large number of systems and technologies with a high level of interactivity.

f Project is customized, not based on a prototype.

g Project requires a high level of coordination, control, and monitoring from start to finish.

\subsubsection{Complexities Associated with Category 1}

Hotels are generally more complex to develop and manage than other building types because they tend to have a considerable diversity of stakeholders with high degrees of power and interest. According to Mosquera [8], a director at the Ampere Hospitality Group, construction of a typical fivestar hotel involves more than 20 experts and consultants, including façade and vertical transportation consultants, wind tunnel specialists (for towers with more than 30 floors), interior design consultants, and kitchen lighting and acoustic specialists, with the number and variety of specialists growing with the hotel classification [8]. The resulting number of different stakeholders can create long communication channels characterized by slow responses, disputes, and conflicts. Beyond their common amenities, hotels are often unique buildings that can distinguish themselves through customized design features that provide, for example, attractive retail areas, unique technological features, or iconic building concepts. As a result, and because hotel projects are fully furnished, the associated costs are very high. Hotels cost four times more per square meter than office developments and require triple the construction time [7]. An interview with a lead project manager revealed that, "a five-star hotel has approximately 6,000 to 8,000 activities executed on-site, [as opposed to] 3,000 to 4,000 activities in three-star hotels and about 1,000 activities for a typical residential building, construction phase only." As a result of the high degree of risk involved in this process, complex planning schedules and estimates must be developed and carefully managed.

Relative to other building projects, hotels also require more complicated systems (electro-mechanical, IT), services, and processes. In turn, the design and execution of such systems requires numerous activities with a high level of interactivity. Such end-to-end overlapping processes require effective coordination and can involve complex and strategic decision-making.

\subsubsection{Complexities Associated with Category 2}

Commercial/office buildings can be described as moderate-complexity projects. The standard practice is to build the core and shell with open floor plans and main services only, leaving the fit-out work to be carried out by the tenant later on. As a result, the complexity of stakeholder diversity and interrelated systems is reduced relative to hotel projects. However, this project scope allows for a high range of customization, particularly in the large, high-cost projects associated with Category 2, Group (A) structures.

\subsubsection{Complexities Associated with Category 3}

For a number of reasons, projects associated with places of worship have a lower complexity than the other project types addressed in this study. In Qatar, the responsible 
governmental authority has issued regulations and guidelines for the construction of worship buildings. These guidelines define design restrictions and specifications, thereby adding smoothness and clarity to the project definition and reducing the degree of possible customization and extreme innovation to create a standard category of construction project. Although the government has developed building design prototypes to facilitate the design and construction processes and maintain improved control over them, there are cases in which the prototypes do not suit the plot conditions and a consultant is secured to execute the design within the defined requirements. Furthermore, worship projects differ slightly from other building projects as they are financed by the government or by private donors (rather than owners). A donor might donate a piece of land for the government to build on or fund the construction of a building on government land. In all cases, worship buildings are supervised and maintained by the government, and donors are obliged to sign an agreement to adhere to approved designs and agreed-upon specifications without changes or interruptions during construction, which enables full supervision by the authorities. As a result of these predefined regulations, design limitations, and controls on donor-based variations, worship buildings have a higher level of standardization. Furthermore, as noted by a lead project manager, the construction of worship projects involves approximately 1,500 on-site activities, which is a relatively small number compared to the other categories. Nevertheless, efficient planning, implementation, control, and monitoring from start to finish are all crucial in sustaining good project performance.

\section{Methodology}

This study conducted an empirical analysis focusing on the time-control difficulties that can cause delays in the identified Qatari construction project categories with different complexity levels. To achieve the study objectives, a qualitative approach using case studies and in-depth interviews was used to obtain focused and extensive data to inform appropriate evaluation results and establishing conclusions. The categories consist of four- and five-star hotels, core and shell office or commercial buildings with two different complexity levels, and worship buildings.

\subsection{Phase One-Developing a Complexity Categorization Framework}

Using a qualitative approach, secondary data were collected from books, internet articles, journals, and other published work. Semi-structured interviews with experts were conducted to understand industry challenges and to obtain summaries of project complexity to appropriately define the scope of the research. The results of the literature review and field expert interviews guided the selection of characteristics used to develop a complexity categorization framework, as detailed in Section 2.2, from which suitable categories were selected to achieve the study objective were selected.

\subsection{Phase Two-Data Collection}

Primary data were gathered using qualitative methods. As the scope was limited to case studies, specific data were collected from project records prior to conducting interviews with project managers. The data were then discussed in-depth over the course of 20 one-on-one interviews with experienced management executives, project managers, discipline engineers, and contract engineers to determine delay factors in the field.

Project delay percentages were calculated based on the project duration and planned-versus-actual finishing dates. The overall delay percentage statistics were then broken down into percentages attributed to specific causes to categorize the delay factors for a more precise analysis. After evaluating the factors applicable to each project, the delays were ranked from highest (most critical) to lowest (least critical) based on the respective assigned percentages to reflect the magnitude of factor impact on project performance. The sample sizes by category are listed Table 2 .

Table 2. Sample size by building category.

\begin{tabular}{ll}
\hline Project category & Number of projects \\
\hline Category 1: Four- to Five-Star Hotels & 5 \\
Category 2: Commercial Offices (Group A) & 5 \\
Category 2: Commercial Offices (Group B) & 5 \\
Category 3: Worship buildings & 10 \\
\hline
\end{tabular}

\section{Results and Analysis}

The severities of the impact of the identified delay factors on the project schedules for each identified category are listed in Table 3. Each delay factor is discussed in detail in the following sections.

\subsection{Change in the Scope of the Construction Project}

In Category $1,74.32 \%$ of the total delay was caused by changes in the scope of the construction project. Such changes are issued in response to newly developing circumstances and are expected during the course of a construction process. Relative to other building projects, hotel construction projects involve more complex development and management for a number of reasons, including the fact that hotels tend to have a diversity of stakeholders with high levels of power and interest, such as the owner, hotel operator, project consultants, contractors, tourism authority, statutory authorities, and financing agency (bank). Later involvement of dominant and powerful stakeholders can increase the risk of changes in scope. Each hotel operator will have their own criteria and requirements that govern project design and services, and the level of requirements will increase with the star rating of the facility. This investigation revealed that the primary causes of changes in scope included appointing an operator after designing the building, obtaining the approval of government 
authorities, and changing the scope of the project from a regular residential building to a five-star hotel during construction. Specifically, change-induced delays required document coordination, revisions, and approvals and resulted in repeated work cycles to implement changes, lengthened communication channels, and disputes regarding whether raised issues constituted legitimate changes in contract scope and how to evaluate the costs of those changes.

Changes in scope represented one of the three most critical delay factors for both Categories 1 and 2 (B), constituting $12.51 \%$ of the total delay in the latter category. This finding emphasizes the severe impact of changes in scope on both small and large projects, as the disruption of an originally agreed upon scope significantly impacts the schedule.

\subsection{Subcontractors}

The second most critical delay factor for Category 1 was related to subcontractors and accounted for $11.17 \%$ of the total delay. This finding reflects the fact that, owing to their nature and size, hotel projects require several specialists. As a result, most of the construction work is performed by subcontractors, which can significantly affect progress and success. High levels of risk are introduced as a result of deploying inexperienced sub-contractors, who can cause delays through poor performance, reworked tasks, poor financial capacity, lack of resources, and delays in material procurement. Accordingly, a higher degree of risk is associated with inadequate main and subcontractors, as the main contractor is obliged to efficiently manage all involved sub-contractors to coordinate and execute the planned scope. An analysis of subcontractor-associated delays in this study revealed that delays emerged from contractual issues between main and subcontractors, delays in the procurement of material by the sub-contractors, and shortages of laborers. However, in many cases in which the main contractor was a big contracting company, the sub-contractor could be supported through supplements to the labor force to cover shortages and accelerate execution.

Delays owing to subcontractors accounted for $34.63 \%$ of the total delay for Category 2 (A) projects. The higher costs of these projects corresponded to an enhanced work scope and a variety of involved parties and specialties. In one case, subcontractor performance played a major role in delay project because a critical issue led to a series of cascading consequences. During the tender process, the owner asked technically qualified bidders to submit discounted offers, the lowest of which was selected. The offer, however, was unrealistic and far below the estimated project budget drawn by the consultant. This added major risks and challenges to the execution of the project. The main contractor attempted to reduce the cost in ways that negatively affected the project by creating a joint venture with another contractor to share risks, costs, and responsibilities. However, the contract was inherently flawed owing to fatal issues in the project's organizational structure and management hierarchy, as the division of the scope and coordination of responsibility within the joint venture was inadequate. In addition, some long-lead items had to be re-procured because cheaper items that did not match the approved specifications were procured unethically by a sub-consultant in an attempt to reduce costs.

\subsection{Final Inspection/Approval by Authorities}

As the third most critical delay factor for Category 1, delays relating to final inspection and approval by the relevant authorities contributed to approximately $6.62 \%$ of the total delay. Government authorities are involved in the project management process until the commissioning and handover of the project. In the final stage of a project, these authorities inspect the executed work to ensure compliance with previously approved designs and to ensure that the authorized standards and regulations have been followed. As this is one of the last stages of a project, delay in modification approval can significantly impact the project schedule and finish date. A strong relation was observed in this study between changes in project scope and the official approval process. Modifications arising from changes in scope must be approved relevant the authorities and, in many cases, the sequential approval of several authorities is required. For projects put on hold for a period of time, it was observed that the number of modifications at the handingover stage was elevated owing to updates in official requirements and standards.

Interestingly, delays arising from final inspection/approval by authorities were found to be the second most critical delay factor for Category 2 (B), accounting for $25.37 \%$ of the total delay in this category. The presence of this factor in two categories with different complexity levels (higher and lower) reflects the importance of managing items related to influential stakeholders and emphasizes the impact of official delays to a project if required knowledge and industry practices are not considered and applied accordingly.

\subsection{Lack of Experience and Low-skilled Contractors}

The commercial/office buildings of Category 2 (A) are often perceived as standard projects with relatively low complexity. This description might be more applicable to Category 2 (B) projects as such an assessment amounts to an underestimation of the expertise required to deliver a project, resulting in mismatches between the skills required to perform tasks and the planned scope. Nineteen percent of the total delays for Category 2 (A) were caused by a lack of contractor experience and low skill levels. Commercial/office buildings should more accurately described as moderatecomplexity projects for which the normal practice is to build the core and shell with open floor plans and provide only main services while the fit-out work is carried out by the tenant later on. As a result, the complexity of stakeholder diversity and interrelated systems is less than that of hotel projects. However, the project scope allows for a wider range of projects and a high degree of customization, particularly in the large, high-cost projects that characterize Category 2 (A). Lack of experience and skills can also create problems in terms of quality, cost, and time. Although it is not necessary 
for the contracting company to have previously executed a project of similar scale and category, it is crucial to evaluate the company's competency, capability, and capacity to execute the intended project.

\subsection{Delayed Material Delivery and Lack of Sufficient Material}

Issues related to delays in material supply and shortages of available materials were found to occur in all of the studied categories, although for different reasons and with varying impacts on the project schedules. Material delay was the third most critical factor for Category 2 (A) and accounted for $14.98 \%$ of the total delay in this group. It was found that poor planning and procurement management by contractors and changes in material specifications during projects played a dominant role in project delays. Materials and - particularly long-lead items-must be planned effectively before beginning construction, and it is vital to have equally qualified alternative suppliers and not depend on a single supplier. Changes in material specifications, particularly for long-lead items in late project stages, can significantly disturb the duration of procurement and delivery activities.

\subsection{Owners' Financial Payments}

Delays in owners' payments were found to be a leading category of delay, constituting $30.80 \%$ of the total delay for Category 2 (B). Construction projects commonly involve a considerable capital outlay, making the distribution of cash flows through efficiently timed payments critical to the progress and success of a project. Category 2 (B) projects consist of low-rise commercial/office buildings (mixed-use) with a standard level of finishes and are therefore of a lower level of complexity than Category 2 (A) projects. The collected data indicated that delays arising from late payments occurred more often in medium and small projects. Generally, as a result of their relatively low contract prices, such projects are fully or partially financed by owners and not by a financing agency. This factor has a greater degree of influence on small building projects because they are commonly awarded to small contractors who depend on cash flows to work, meaning that delayed payments represent a financial burden. Moreover, such projects are commonly run by the owners themselves or by a technically unqualified representative; this can cause unnecessary clashes between the contracting parties, which is usually reflected in payment delays. Other common causes of delays include the failure to tie projects to a "must achieve" deadline and owners who are not in a rush or under an obligation to assign a fixed delivery date for an operator or tenant. Yet another common cause of delays is disagreement regarding contractual factors between owners and contractors who have low and average levels of awareness, respectively, of the related payment terms, particularly when the contractual team does not adhere to or have sufficient knowledge of the terms and conditions and expects that disputes can be handled in a casual manner.

This type of delay was found to be the top delay factor in Category 3 projects. As noted above, worship projects in Qatar are financed by either the government or private donors. The latter are associated a higher risk of delay because governmental control over payments is reduced relative to their own funding levels. The impact of this factor was found to account for $38.46 \%$ of the total delay in this category for a number of reasons. For example, if a donor becomes financially incapable of supplying funding, the authorities will require time to validate their financial condition and support their claim to financing of the remaining work through the government. Such governmental intervention lengthens the process because certain procedures must be followed and, in the meantime, on-site work halts with the last payment made.

\subsection{Inadequate Planning}

Inadequate planning by contractors was found to be one of the most critical delay factors for Category 3, corresponding to $19.55 \%$ of the total delay in this category. In many cases, worship projects are awarded directly to contractors by the government authority responsible for doing so based on direct donor selection or according to awarding to the lowest qualified bidder, which encourages bidders to submit undercost proposals. Because of the low estimated project cost ceiling in this category, most bidding contractors can be classified as low- to medium-class contractors, and some do not have adequate skills or management capabilities to successfully execute projects within the planned period. As a result, planned activity schedules cannot be met with the estimated activity resources (manpower, equipment, and material) required to execute the work. Indeed, inadequate resource estimation for the volume of work was a common and emphasized occurrence in the interviews conducted for this study.

\subsection{Unnecessary Donor Interference}

Unnecessary interference was observed to have a significant impact on Category 3 projects, accounting for $19.29 \%$ of the total delay in this category. Donor interference can significantly disturb project progress in many ways. As discussed earlier, any conflict or clash with predefined requirements can hinder progress because worship projects in Qatar are executed under governmental procedures and requirements. In one case, the donor refused to comply with one of the authority's regulations at the handover stage which delayed the completion of the project. Furthermore, the donor held up the contractor's payments while this suspension was in place. This case represents an example of payment delay caused by disagreement and project delay caused by the need to negotiate with the authorities to obtain an exception to regulations. 
Table 3. Comparison of impacts of delay factors on time schedules within respective categories.

\begin{tabular}{|c|c|c|c|c|}
\hline Delay Factor & $\begin{array}{l}\text { Category } \\
1(\%)\end{array}$ & $\begin{array}{l}\text { Category } 2(\%) \\
\text { Group A }\end{array}$ & $\begin{array}{l}\text { Category } 2(\%) \\
\text { Group B }\end{array}$ & $\begin{array}{l}\text { Category } 3 \\
(\%)\end{array}$ \\
\hline Variations in the scope of the construction project & 74.32 & 7.05 & 12.51 & \\
\hline Modifications required by government authorities to obtain building permits & 3.60 & 14.67 & & \\
\hline Sub-contractors & 11.17 & 34.63 & 8.93 & \\
\hline Lack of experience and low-skilled contractors & 0.96 & 19.12 & & 4.33 \\
\hline Insufficient execution of plan by contractor & & 1.59 & & 6.97 \\
\hline Lack of labor force & 0.96 & & & \\
\hline Poor productivity of hired labor & & 0.96 & & \\
\hline Inefficient planning by contractor & & 0.64 & & 19.55 \\
\hline Final inspection/approval by authorities & 6.62 & 5.19 & 25.37 & \\
\hline Mistakes in design by consultant & 0.67 & 1.16 & 0.00 & \\
\hline Late material delivery or lack of sufficient material & 0.49 & 14.98 & 12.41 & 7.68 \\
\hline Difficulties in obtaining different parties' approval & 0.97 & & & \\
\hline Owners' financial payments & & & 30.80 & 38.46 \\
\hline Improper site conditions / obstacles & 0.24 & & 9.97 & 3.72 \\
\hline Unnecessary interference by the owner/donator in various project areas & & & & 19.29 \\
\hline
\end{tabular}

Note: Percentages reflect the severity of the delay factor on the project schedule.

\section{Discussion of Critical Factors and Comparison with Projects in Other Countries}

Some delay factors were found to recur across categories, particularly among projects with similar complexity levels and characteristics, as shown in Table 4.

Table 4. Comparison of critical delay factors across studied categories.

\begin{tabular}{llll}
\hline Category 1 & Category 2 & Group B: & Category 3 \\
\cline { 2 - 3 } $\begin{array}{l}\text { 1. Changes in the scope of the } \\
\text { construction project }\end{array}$ & $\begin{array}{l}\text { 1. Subcontractors } \\
\text { 2. Subcontractors }\end{array}$ & $\begin{array}{l}\text { 1. Owners' financial payments } \\
\text { level of contractor }\end{array}$ & 1. Owners' financial payments \\
$\begin{array}{llll}\text { 3. Final inspection/approval by } \\
\text { authorities }\end{array}$ & $\begin{array}{l}\text { 3. Delayed material delivery and lack } \\
\text { of availability of sufficient material }\end{array}$ & $\begin{array}{l}\text { 2. Final inspection/approval by } \\
\text { authorities } \\
\text { 3. Changes in the scope of the }\end{array}$ & $\begin{array}{l}\text { 2. Inefficient planning by the contractor } \\
\text { 3. Unnecessary interference of the owner } \\
\text { in the different areas of the project }\end{array}$ \\
\hline
\end{tabular}

A comparison of the performance of the respective removed revealed that delays increased with complexity, as categories in terms of delay with outlying/unusual cases shown in Figure 1.

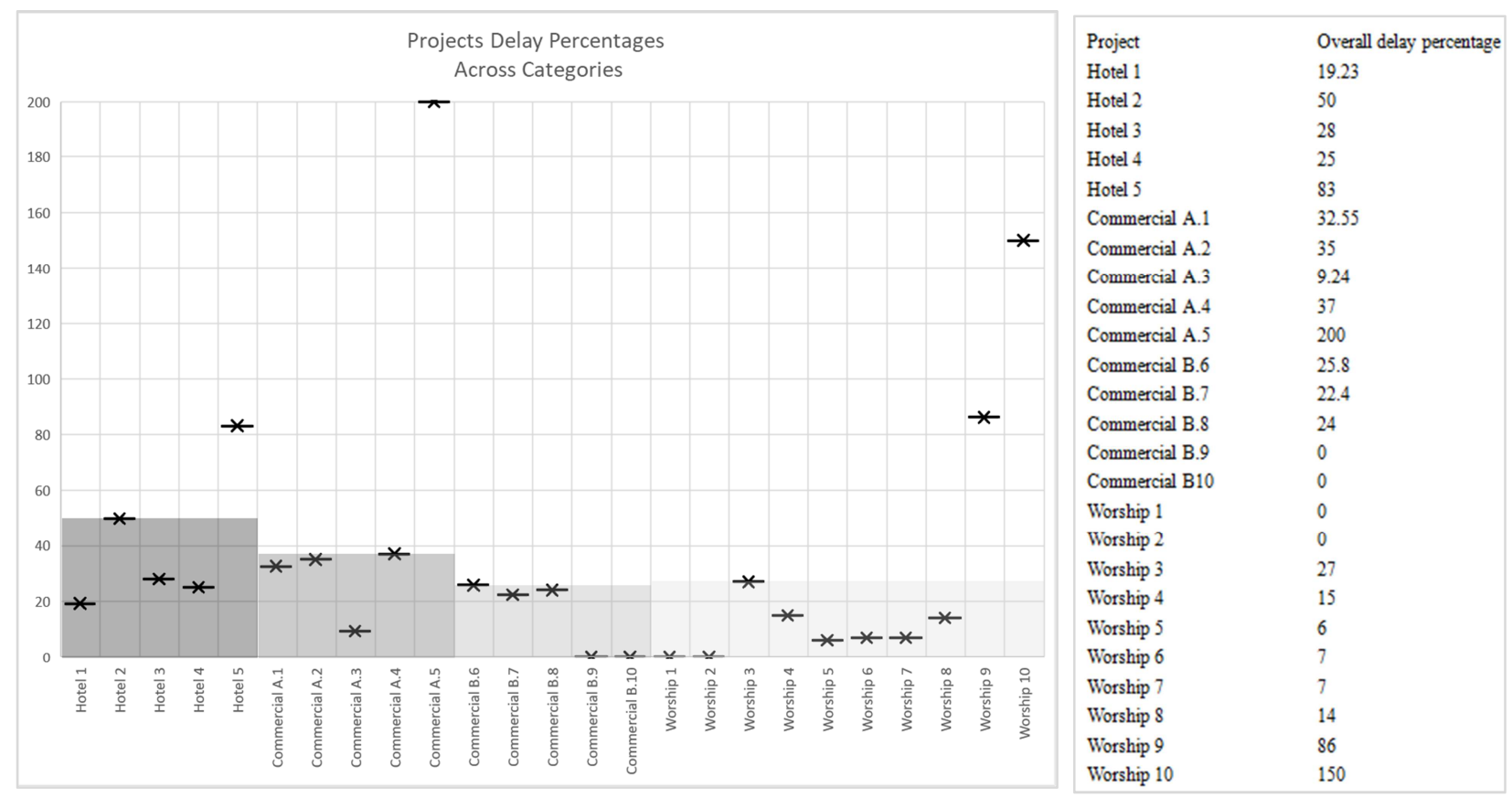

Note: Project delay percentages were calculated using project duration and planned-versus-actual finishing dates.

Figure 1. Comparison of delay percentages across categories in Qatar. 
For all project categories, changes in scope were found to have a significant effect on schedule delay as a result of the need for repeated evaluation, approval, and implementation. The effects changes in scope were exacerbated when the project's critical path was impacted. It was further shown that change-based delays in projects with higher complexity in terms of stakeholder diversity resulted from inadequate stakeholder management, while change-based delays in lower-complexity projects resulted from improper scope definition. A review of projects in developing countries by Islam and Trigunarsyah [9] found that, for all project classification types, changes in scope and financial issues during construction were the most frequent and critical causes of delay. Two studies on large building construction projects in Saudi Arabia by Assaf et al. in 1995 and 2006 [10, 11] also noted changes in scope as a primary critical delay factor in large construction projects

Delays arising from subcontractor issues were found to be a dominant factor in large projects. Owing to the high number of subcontractors involved in executing the larger and more varied scope of work in such projects, the risks of delay by subcontractors are higher. In $\mathrm{n}$ the cases examined in this study, a high project cost was found to be an indication of larger project scope. A 2012 study by Papadopoulou and Park [12] on the causes of cost overruns in a large transport infrastructure project in Asia revealed that, in addition to the significance of project size, awarding contracts to the lowest bidder, site conditions, and incompetent subcontractors were the top three causes of cost overruns. The results of this study also indicated a moderate correlation between cost overrun and project size, with the result that large building projects were frequently delayed by subcontractors. Thus, understanding the complexity dimensions of large projects is essential to selecting the appropriate project organizational form and expertise.

Delay associated with official approval was found to be a critical factor in all project categories, particularly in later stages. To ensure compliance with local standards, regulations, and policies, official involvement continues until the commissioning and handover of a project, resulting in a delay factor that was repeated among both high- and lowcomplexity projects for a number of reasons. The results of study indicated that projects in all categories experienced significant changes in scope, making the need for official approval a sub-cause of delay. Furthermore, inexperienced contractors were found to be subject to official delays as a result of poor planning and lack of the knowledge needed to ensure compliance with all standards, regulations, and requirements prior to and during inspection. A brief study of the construction industry in the U.S. state of Florida by Ahmed et al. [13] found that code-related delay, including building permit approvals, inspections, and changes in laws and regulations by the government, was the most critical category of delay. The study recommended streamlining the approval process as much as possible [13] and indicated that code-related delay is a critical problem even in developed countries such as the United States.

Delay arising from the owner's financial payments was found to be the leading factor in low- to medium-size projects with relatively low complexity levels, i.e., Categories 2 (B) and 3. Previous studies have revealed that the issue of late payments is present both in developing countries such as Ghana and in developed countries such as Australia and the United Kingdom [14]. In many cases, the contractor's awareness level and adherence to contractual guidelines present a common problem in which the contractor's technical and contractual team do not adhere to or have sufficient knowledge of contract terms and conditions and expect disputes to be handled in a casual manner, resulting in a negative impact on payments [15]. When investigating the different causes behind this delay, the general conditions of contracts were often found to be silent with respect to payments and tended to favor owners. For example, the contractor often had no right to stop or slow work owing to delayed payment and was not allowed to apply interest to delayed payment, stipulations that added burdens upon the contractor's financial situation. Although such conditions were not explicitly stated in the contracts, they were covered under the terms of payment article, under which employers were generally not liable for interest on delayed payments while liquidated damages articles could be applied in the case of contractor delays.

\section{Recommendations}

This study found significant delay factors common to all building categories, including delays owing to changes in scope and delays owing to inspection/approval by authorities. This section presents recommendations related to these two factors, which occurred in high and low-complexity projects alike.

\subsection{Factor 1: Delays Owing to Owners' Changes in Scope}

Although changes in project scope cannot be avoided entirely, their impacts can be mitigated or minimized using management practices. In this study, two project management knowledge areas were found to be crucial for managing changes in scope: project stakeholder management and project scope management.

Recommendation 1: Minimize variations through proper management of project stakeholders.

The Project Management Body of Knowledge (PMBOK Guide) identifies a set of processes for managing project stakeholders. Although these processes are discrete, they interact and overlap throughout the course of a project. Furthermore, agility in decision-making minimizes the impact of delays on project schedules for situations requiring the active engagement of stakeholders. For example, in some Category 1 projects, rather than going through long communication chains and layers of, the owner paid the hotel operator's representative to be present with the local consultant's team in order to directly discuss and implement requirements and changes. However, such project teams must 
still analyze the impact of costs and extra fees as well as the cost of delays.

Recommendation 2: Reduce gaps through appropriate definition of the project scope.The Project Scope Management section of the PMBOK Guide defines six processes that can be used as guides for managing project scope. To minimize the chances of required changes, the project team must define the scope by collating and appropriately analyzing requirements according to the client's interests. It is critical to include and manage the conflicting needs and expectations of project stakeholders when collating their requirements. The documented requirements can then form the basis for defining and developing the project scope, including boundaries and exclusions, to maintain proper control of the project.

Recommendation 3: Raise the client's awareness of the impact of changes in scope. Before changes can be implemented, the client must be made aware of their consequences through an evaluation of the impact on project cost, schedule, and other related performance aspects.

Recommendation 4: Manage interfaces properly.

Later project changes have the advantage of building on previous gaps and design clashes. As a very effective strategy, contractors can be included in the project process prior to officially issuing a change by, for example, issuing an advanced copy of the change package for contractor information and review. The contractor's observations can then be captured as needed to resolve any design issues that might arise later. This strategy also allows the contractor to start contacting their vendors to manage the pricing process in advance, thereby reducing the change evaluation duration.

Recommendation 5: Split work packages to reduce the impact of delays in one package on other activities.

Instead of sequentially conducting work packages, it is recommended that some activities be performed in parallel to reduce the overall completion time.

\subsection{Factor 2: Delays Owing to Final Inspection/Approval by Authorities}

Recommendation 6: Formulate a comprehensive plan by considering authorities' requirements, evolving changes, and time lags. To mitigate delays in the final inspection/approval by authorities, the project team must:

1. Ensure compliance with all government standards, regulations, and requirements before and during the inspection;

2. Monitor changes and updates in all specifications and regulations, particularly to avoid changes in projects that have been on hold for a long time or that have long execution periods;

3. Given the uncertainty in the scheduling of inspection visits by authorities, dedicate adequate time for inspection and approval activities in planning the project schedule and assign experienced personnel to follow up on these activities;

4. Plan the work execution in terms of the time needed to raise an Inspection Request (IR). For example, the contractor can be asked to provide a look-ahead schedule. For example, if it is possible to complete the work required for official inspection within two weeks, the supervision consultant should raise an IR two weeks in advance. This will take less time than raising an IR after completing the work. However, expert judgment is required to adequately estimate the required time, and the work should still be efficiently managed to allow for finishing as planned;

5. As advised by the project managers interviewed for this study, plan to complete work that is to be inspected by authorities in advance. This will allow sufficient time to incorporate the authorities' comments and receive approvals in time for the handover.

\section{Conclusions and Further Research}

\subsection{Conclusions}

All construction projects pose risks of varying natures and degrees of complexity, with delay posing a significant risk in the industry. The results of this study emphasize the importance of identifying the delay factors in the early stages to properly manage construction projects and ensure timely performance. In this study, common delay factors and their impacts on specific project categories were studied to link these factors to different project characteristics and establish a broader conclusion that can be applied to projects in general. To better understand the underlying characteristics of project delay, the focus of this study was on project complexity level. In order to link the delay factors associated with different levels of complexity, a framework was established to compare performance in four building construction project complexity categories. For each category, the top three critical factors were identified by comparing the weight of each delay factor relative to the overall delay in that category. The identified categories, especially those with similar complexity levels, were found to have common factors affecting their schedule performance. For instance, the schedules of Category 1 and 2 (A) projects were significantly affected by subcontractor issues arising from complexities in terms of the associated stakeholder diversity, project size, and costs. Alternatively, some factors were repeated across relatively high- and lowcomplexity levels, including changes in the scope of the project and delay owing to final inspection/approval by authorities, which were important in both Categories 1 and 2 (B). These findings indicate that the impact of some factors, such as changes in scope, is significant in all building categories due to their extensive departure from the associated project plans. The recurrence of delays associated with final inspection/approval by authorities highlights two important findings, namely, the critical importance of delays in the final stage (as the final target finish date is approached) and the significant impact of powerful stakeholders on project performance.

Correlations of performance by category according to delays, 
with exceptional outlier cases excluded, revealed that delays tended to increase with complexity. However, for both largeand small-scale projects, risk identification of potential causes of delay found to be important throughout the construction process to enable the proactive adoption of necessary mitigation measures. In the data collection process undertaken as a part of this study, many companies were found to be lacking in appropriate risk management practices and records of lessons learned. To avoid delays, proper management and transfer of knowledge should be embedded into company culture and tools should be tailored to project-specific characteristics such as size, complexity, and importance.

\subsection{Limitations}

To achieve the stated objectives, the scope of this study was limited to three categories of building projects with four complexity levels. In future investigations of the nature and impact of various types of complexity on the construction industry, a wider scope of research should be applied to include additional types of projects with more granularity. In addition, the sample evaluated in this study was limited to twenty-five projects, with data collected from three unique providers: a consultancy/supervision company, a contracting company, and the government authority. In future research, this data set should be expanded by studying a larger sample of projects undertaken by different companies in Qatar and elsewhere to generalize the findings. This will also aid in further investigation of the differences observed in this study and help to confirm the presented hypotheses.

\subsection{Further Research}

While this study focused on delay factors, further research should address the factors underlying cost overruns and their correlations with delay and complexity level to formulate appropriate mitigation measures. Alternatively, the top delay factors for the identified complexity levels in Qatari projects could be compared with those from other developed and developing countries. Additional areas for future research include studying and measuring the effectiveness of specific mitigation measures on project performance.

\section{References}

[1] Lissack, M., P. Cilliers and K. A. Richardson (2001). Complexity science: A "gray" science for the "stuff in between." Emergence, 3 (2): 6-18. doi: 10.1207/s15327000em0302_02

[2] Wood, H. and K. Gidado (2008). Project complexity in construction. COBRA 2008, 1-13.
[3] Merry, U. (1995). "Coping with uncertainty - Insights from the new sciences of chaos, self-organization and complexity." Westport: Praeger Publications.

[4] Mills, A. (2001). A systematic approach to risk management for construction. Struct. Surv., 19: 254-252.

[5] Baccarini, D. (1996). The concept of project complexity - A review. Int. J. Constr. Manag., 14 (4): 201-204.

[6] Buys, F. (2015). "Five causes of project delay and cost overrun, and their mitigation measures." https://www.linkedin.com/pulse/five-causes-project-delaycost-overrun-mitigation-measures-buys. Accessed May 19, 2018.

[7] Gidado, K. (1996). Project complexity: The focal point of construction production planning. Constr. Manag. Econ., 14 (3): 213-225. doi: 10.1080/014461996373476

[8] Mosquera, L. (2015). Understanding the hotel development process. Retrieved from https://www.linkedin.com/pulse/understanding-hoteldevelopment-process-lucienne-mosquera-mih

[9] Islam, M. S. and B. Trigunarsyah (2017). Construction delays in developing countries: A review. J. Constr. Eng. M. ASCE., 7 (1): 1-12. doi: 10.6106/jcepm.2017.3.30.001

[10] Assaf, S. A. and S. Al-Hejji (2006). Causes of delay in large construction projects. Int. J. Constr. Proj. Manag., 24 (4): 349 357.

[11] Assaf, S. A., M. Al-Khalil, and M. Al-Hazmi (1995). Causes of delay in large building construction projects. J. Manag. Eng., 11: 45-50.

[12] Papadopoulou, T. C. and Y. I. Park (2012). Causes of cost overruns in transport infrastructure projects in Asia: Their significance and relationship with project size. Built Environ. Proj. Asset Manag., 2: 195-216. doi: $10.1108 / 20441241211280873$

[13] Ahmed, S. M., S. Azhar, P. Kappagantula and D. Gollapudi (2003). "Delays in construction: A brief study of the Florida construction industry." In ASC Proc. of the $39^{\text {th }}$ Annual Conf., 257-266. Clemson, South Carolina: Clemson University.

[14] Ansah, S. K. (2011). Causes and effects of delayed payments by clients on construction projects in Ghana. J. Constr. Proj. Manag. and Innov., 1 (1): 27-45.

[15] Okeyo, M. P., C. M. Rambo and P. A. Odundo. (2015). Effects of delayed payment of contractors on the completion of infrastructural projects: A case of Sondu-Miriu Hydropower Project, Kisumu County, Kenya." Chinese Bus. Rev., 14 (7): 325-336. 